\title{
Mastering Development of Networks: Critical Skills and Knowledge
}

\author{
Seppo Sirkemaa \\ Turku School of Economics and Business Administration, \\ Pori Unit, Pori, Finland
}

\section{seppo.sirkemaa@pori.tukkk.fi}

\begin{abstract}
Most information systems rely on networks in sharing data and information. Here we focus on networks and discuss skills and knowledge that are needed in the network development process.

In general, information systems development is based on existing systems. Especially networks follow this rule, because all earlier development work and decisions impact the reliability and flexibility of the network. This makes management of network development and in a wider perspective information systems development an important challenge.

Today computers and applications need more bandwidth than ever. Existing networks need to be rebuilt so that there would be more capacity available. One possible solution is network traffic management; the other alternative is changing to faster network technology. However, it is likely that in the future the demand for bandwidth will increase further. Therefore we argue that the skills and knowledge of the persons in the development process is a critical resource.
\end{abstract}

Keywords: information technology, infrastructure, development, skills, knowledge

\section{Introduction}

Networks are important because most information systems are based on sharing data and information. In a typical organization there are several applications that exchange data. In addition, many systems interconnect with systems that are in another geographical location, or in another organization. As a result, the amount of users that require, create or simply share data that is in another system is significant even in a small or medium-sized organization. However, sharing should happen seamlessly to the user (Rockart, Earl, \& Ross, 1996).

The concept of networks is closely related to infrastructure. Information technology infrastructure (IT infrastructure) is the basic, shared platform for all business applications (McKay, \& Brockway, 1989; Broadbent, Weill, O’Brien, \& Neo, 1996). It has a organization-wide impact, and infrastructure-related decisions have future consequences for several years (Galliers, 1993). The IT infrastructure is a combination of both technical components and human expertise, and both are needed to provide services for business needs (Davenport, \& Linder, 1994; Broadbent, Weill, O’Brien, \& Neo, 1996; Byrd, \& Turner, 2000).

In most cases are investments in information technology considerable (Turnbull, 1991; Dos Santos, \& Sussman, 2000), and this is also the case with infrastructure and networks (Broadbent, Weill, O'Brien, \& Neo, 1996; Weill, \& Broadbent, 1998, 23-39). When investments are being planned one of the main concerns is that new technology should integrate into the existing technological infrastructure (Hanseth, 1996). Consequently, the management of information technology investments and network development is a important challenge. 


\section{Mastering Development of Networks}

\section{Research Focus}

Philosophically, technology is considered to be a resource that impacts the organization through human choice and interaction (Orlikowski, 1992). The human role is critical to management of information technology. In addition, these management practices have been developed over time and they are unique in each organization (Mata, Fuerst, \& Barney, 1995).

Often the border between networks in the organization and other, larger networks is hard to define. As an example Internet-based information systems fall into both categories as they may benefit the organizations internal information needs (Intranet-systems) and at the same time act as a route to other organizations and resources internationally. This makes researching the management of networks rather cha $1-$ lenging.

This research focuses on planning and managing networks. Our ideas are based on both literature and experiences from a network development process in a case organization. Here we concentrate on skills and knowledge in the network development. In addition, we discuss stages in network development.

\section{Skills Involved in Network Development}

In this chapter we are interested in skills that are needed in network development. In general, the persons who are involved in IT development should possess skills and knowledge in a wide area (Dos Santos, \& Sussman, 2000). These can be divided into three classes: technical, business and interpersonal skills (Lee, Trauth, \& Farwell, 1995; Todd, McKeen, \& Gallupe, 1995). In addition, Feeny and Willcocks (1998) found two more perspectives, value orientation and time horizon (see Figure 1).

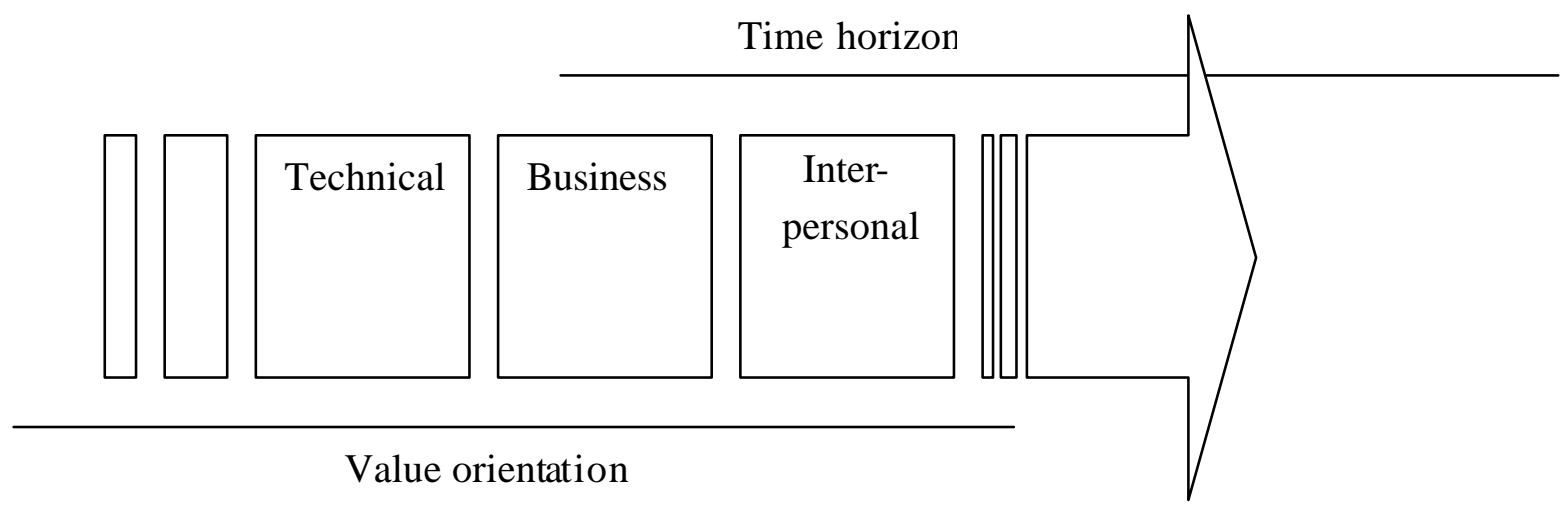

Figure 1: Domains of skills and knowledge

Here we look at these skills from the viewpoint of network and IT infrastructure development and management. The knowledge and skills of people involved in the development is considered as a critical factor for successful information technology development and use (Orlikowski, 1992; Lee, Trauth, \& Farwell, 1995; Byrd, \& Turner, 2000).

\section{Technical Skills}

Technical skills are important in network development because knowledge of technology in question is required in order to make justified decisions. Technical knowledge and expertise is needed at all mangerial levels that are involved (Byrd, \& Turner, 2000). Also a mutual understanding of the development area or application of the technology is important. 
Technical skills should not only be seen as limited technical knowledge like knowledge of technical devices, solutions and alternatives. There is also an interpersonal dimension involved as development alternatives and possibilities are often mapped during discussions with outside experts and vendors. Technical knowledge, interpersonal skills and experience are needed to judge a technology, product and a solution. Understanding the technological capability can also be important in monitoring partner and vendor relationships. Here previous experiences of a technology or a partner are in an important role.

\section{Business Skills}

The importance of business skills in IT development is often emphasized. According to Feeny and Willcocks (1998) business skills are linked to following capabilities: leadership, business systems thinking, relationship building, informed buying and vendor development. Management skills are increasingly important also in the IT domain (Boynton, Zmud, \& Jacobs, 1994; Lee, Trauth, \& Farwell, 1995; Byrd, $\&$ Turner, 2000). As Feeny and Willcocks (1998) motice

"IS professionals deliver core IS capabilities by exploiting assets that previously enabled their successful IS careers: rapidly absorbing new information, building mental models of how things work, and using these models for exploration."

Consequently, one can wonder how IS-people can manage and develop systems that will ult imately be used to business purposes. It could even be argued that IT development has so many business skills involved, that business people and managers could develop better ne tworks than IS-people.

\section{Interpersonal Skills}

Interpersonal skills are important in both internal and external relationships. IS people need to convince the business people that they understand their goals, processes and concerns, and that information technology helps in achieving business goals. Interaction is vital (Ross, Beath, \& Goodhue, 1996): the more there is discussion and cooperation, the stronger the mutual understanding will become. This should result in better planning of new systems, and more sophisticated use of existing information technology.

In general, also people in the IS department should have good interpersonal skills, and be able to talk "normal" language with business people instead of technical jargon. However, technicians are an interesting expectation. When technical assistance and help is really needed technical expertise is considered more valuable that interpersonal skills. Technicians are not usually considered to be very good in interpersonal skills, despite this they are tolerated because they can make things work.

In external relationships are interpersonal skills important in discussions and negotiations with outside experts, partners and vendors. Interpersonal skills are especially at stake when showing outside service providers and internal business people that their values and problems are respected and understood.

\section{Value and Time Horizon}

Information technology involves large investments in technology that may be used only to a given purpose (Dos Santos, \& Sussman, 2000). However, developers should build systems that are robust and operate reliably for a long time (Keen, 1991; Keen, \& Cummins, 1994). The systems should also be flexible so that future expansions and change in needs can be incorporated (Hanseth, 1996). This highlights the importance of development of a system that serves as a basis for operations, but still is open for modifications. The need for an IS-strategy is obvious - it helps in operative decisions and brings a longer time perspective to IT development.

How should IT skills in network development reflect these requirements? Obviously, some skills are more oriented to short-term interests than others. In technical maintenance the perspective is short as the goal is to solve a problem as soon as possible. Therefore the system should be build so that it is easy to 


\section{Mastering Development of Networks}

locate and solve problems when they occur. Weaknesses and bottlenecks should be mapped and alternative recovery plans need to be done in order to increase the reliability and robustness of the network. This mapping calls for skills in finding solutions to various potential technical problems.

However, also a longer time perspective is important in network development. Business thinking, architecture planning, vendor development and contract monitoring have their emphasis on long-term positio ning. The same long-term interest can be seen in developing business processes that support strategic goals, or planning technical architecture that is open and flexible in the future.

\section{Development Stages}

Network management is in this paper divided into network development and maintenance related activities. However, the main emphasis is on development and planning work. Development involves improving the original system and developing a solution that better meets the needs (Checkland, \& Scholes, 1999). Information systems develo pment can further be divided into (Hoffer, George, \& Valacich, 2001; Checkland, \& Scholes, 1999) organization of the process, mapping of the organization, mapping of the present state of information processing and the actual design process. At this point the choices should be made according to organizations IS strategy. Here we apply these steps into network development.

The first task in the network development process is to organize the design process. Here interactive and business skills are important. Organizing the development group involves naming the members from the IS department and other departments. Often the development group includes IS people, business mana gers and other key people, users and outside consultants. The key people from organization's other departments and units should to be picked based on the skills, role and interest that these persons have related to the system that is about to be developed. Naturally, this applies to selecting IS people as well. If the organization has earlier done IS-related development, the key people from the IS-department and other departments may be well known.

The development group should have enough information in order to evaluate different development alternatives and make design choices. Therefore outside sources of information are important. These may include ideas and advice from consultants, academic people or experts in some particular area. Also conferences, professional journals and Internet can give ideas of possibilities and limitations in different technologies.

Interaction is recognized as one of the primary requirements for successful implementation (King, 1978). Therefore discussions and changing opinions are important in the development work. There are other factors as well, such as group composition, personal characteristics of the group members and rewarding methods that affect the performance and interaction of the development group. However, enhancing group interaction, innovative thinking and working methods are important, but may not automatically ensure better results.

The second step in the development process is mapping the organization. Business skills and also interactive skills are critical at this point. Mapping the organization refers to learning to understand what are the key sectors of operations, the most important functions, how the information flows from one department and person to others etc. It is vital to understand how the organization operates because computer networks impact the flow of information. The importance of fitting IS to the organizational cannot be overemphasized (Schein, 1986; Markus, 1991). Consequently, the development group should involve in the development process people who know and can explain the organizational goals and processes, at both operational and strategic levels, to all the participating people.

The existing information system is the starting point for the practical development process. The hardware, software and network infrastructure in the organization need to be described. The description 
should give the people in the development process a comprehensive picture of the information system. It should clarify

- the hardware: how many and what types of computers, servers and printers there are.

- the software: workstation operating systems and network operating systems, applications including both office suites and business applications.

- the network: physical layout, cabling and active components.

- the communications: connections to satellite offices, bandwidth.

- most important partners: operators, cooperative partnerships, service agreements.

The networking technologies are both complex and evolving. Building the network is an expensive investment and this is why it should be based on comprehensive planning. There are often several alternatives; even choosing between transmission technology is not a straightforward issue as distances, locations and speed requirements make an unique combination (Miller, 1991). It is also important that the new technology fits into the previously installed network and IT infrastructure (Hanseth, 1996).

In most cases the result of development work is a combination of old and new networks and networking technology. Building a robust and reliable system is a challenge for the development group. Therefore this third step, the actual design process, calls for technical skills. Developers should know the specifications and limitations of both existing and new technology in order to plan a network that meets business requirements. As Nadig and Hard (1993) notice,

\section{"decisions should be based on which technology best meets the objectives and not solely on the latest technology".}

Earlier experiences of networks, network technologies and vendors play also an important role. Decisions are further affected by issues like network expandability and pricing. The price range for different network components may be wide. This means that the organization should have a strategy for ISinvestments: will investments favor state-of-the-art and high quality technology which will be expensive or will the needs be met with more prone off-the-self technology that can be a considerably less expensive solution.

The whole system can be purchased from one vendor. The other alternative is to use several partners in the project, for example to purchase network components from one place, software from another and use several outside experts to give opinions in the planning process. The choice between vendors, partners and other outside service resources is also a strategic question and it affects the IT maintenance and development work in the future.

\section{Network Development in the Case Organization}

The expansion of networks has been rapid. When the first networks were built it was not known that they would expand as much as they have. The expansion and growth of the networks has at least in some cases been poorly planned - or not planned at all. One reason for this has been that it has been easy to expand the network by just adding more and more new workstations to existing network. Let us look at network development in a case organization during the past decade.

In the case organization the network connected 18 microcomputers and one server in 1991, in 1994 there were already over one hundred microcomputers in the network and several servers. Today the case organization has about 300 computers in the network. As the workstations and users typically share the network media, new workstations and more simultaneous users slow down the network operations - resulting a need for more speed and capacity in the network. 


\section{Mastering Development of Networks}

What about the IT-department in the case organization? The first full-time IT person was hired in 1995. Before that IT related activities were developed by non-professionals who actually were supposed to do other tasks in the organization. At this point most service and maintenance work was done by vendors or other outside companies. Even though the task of the IT person was to develop the system together with top management, he was more a technician who is expert in technical issues and could only talk technical jargon.

Network kept growing as more servers and services were added. The importance of managing IT deve lopment and maintenance was realized when several departments of the same organization and a number of other outside organizations were connected to the same network in 1996. The network provided now access to the Internet, and outside organizations were able to share the connection. However, the network needed management as it was continuously expanding and the costs had to be shared and managed. There were also performance related problems in the network. The number of users had increased considerably, and the added traffic slowed the network down. It was hopeless to access resources through the network during most active business hours. The IT person was not able to do everything that users asked for, and more time was needed to administrative work, meetings and planning.

The need for management of the whole IT domain was clear, which lead to creation of the IT-managers post. In this case IT-manager was responsible for the whole IT in the organization. The IT staff grew to a total of three full- time IT persons. In addition, there are also contact persons in each department who act as a link between IT department and the users in their department. Now development is done in a group where IT people, top managers and other key persons from each department work together on a weekly basis. One of the first tasks for the development group was to develop a IS -strategy.

This case shows at least three facts:

1. Networks expand and this will happen even without planning. Here the system grew from a network of 18 microcomputers to a network of over 300 microcomputers, several servers, connections to the Internet and about 20 different outside departments and offices. All this happened without proper planning; new computers and departments were simply added to existing system.

2. Planning could lead to better functionality. Planning is needed desperately only when the network faces serious problems like frequent down-times, lost connections, users unable to do their work due to IS, too long time to wait for network support to solve a problem etc. Problems usually add up, so poorly planned systems may have plenty of all kinds of problems.

3. Management is needed in order to develop the network. It is hard to develop the network if there is no IS-management. Development and management of the IS resource calls for strategy and development that involves also key persons from top management and departments.

When we look at the skills involved in the network development of the case organization, we notice that the first full-time IT person was primarily a technically skilled person. Interactive skills and knowledge in the business domain were not present in the early development stages. Discussions with the top ma nagement and planning together with the departmental management and users were not common before the IT manager was appointed. After this point the IT department and network planning became more interactive inside the organization, and involved more outside sources of information.

This case seems to contradict the earlier presentation of skills that are needed in different stages of network planning. We argued that interactive and business skills are needed in the first stages of network planning. Technical skills are needed but the first steps in development call for discussions and mutual understanding between the IT people and the business people in the organization so that technology supports organizational goals in the best possible way. 
In the case organization the network has been built primarily from the technical perspective. At this time falling IT prices and better, more reliable devices were introduced to the IT market. The goal in IT development was to give every user a computer and an access to common resources. In this organization IS strategy was not formulated. However, discussions with the top managers reveal that today network development would not be possible without continuous discussion with the stakeholders involved. The network impacts so profoundly all departments, functions and users that it is crucial that the IT is being developed so that it integrates into organization and supports business goals. The importance of common goals has been understood in the case organization.

\section{Future Directions}

In general, computers are very powerful today when compared to models that are few years old. Similarly, applications are increasingly graphics-intensive. However, when new computers and applications are connected to the network, they may work as slow as the older computers. This is because network is basically a shared media where existing capacity - or bandwidth - is shared among simultaneous users. This is a challenge to network development. One solution is network traffic management, which refers to techniques that isolate traffic from different functions and departments, and guarantee a predefined capacity to a certain application or group of users (Stallings, 2000; Comer, 2001). Other solution is faster network technology, which means moving from Ethernet to FastEthernet, and GigabitEthernet (Stallings, 2000). In this case network bandwidth is increased so that there is more capacity available. Often both network traffic management and moving to faster technobgies are used at the same time.

In both alternatives the network needs to be rebuild. At this point it is time to prepare for growth because in the future the computing power of microcomputers will continue to grow and there will become more pressure on high-bandwidth communication needs. However, the past has shown that the new faster networks will not live long. It is therefore likely that after a few years the network may be replaced with faster network that uses more enhanced technology than the ones that are planned and installed today.

\section{Discussion}

Network development - and IT development in general - is more than making right technological choices. The development process and management of it is a challenge, so is dealing with user demands. Also IS-people and vendors have to be somehow informed and kept in close contact with the development process. As the technology behind the networks is changing, the people involved in development should have knowledge of the changes and trends in network-technology itself. Otherwise the organization may lose business opportunities or invest in obsolete technology. Consequently, the human factor skills and knowledge of the persons in the development group is a critical issue in network development.

We argue that technical, business and interactive skills and knowledge are important in network development. The relative importance of these skills varies depending on the development stage. Interactive and business skills are most important in the first steps of the development process when the project group is being gathered and the group members develop a mutual understanding of the development goals. Technical skills and knowledge is needed when different technologies are being evaluated and the actual system is being planned. However, as the case ind icates development can happen also primarily from technical perspective. The case also shows that when the network grows the management of it becomes increasingly challenging. Ultimately, IT needs to support organizational goals and therefore the role of the network needs to be discussed. Discussion is important for understanding the potential of networking and IT in the organization. This is a basis for successful IT development and utilization. 


\section{References}

Boynton, A.C., Zmud, R.W., \& Jacobs, G.C. (1994). The Influence of IT Management Practice on IT Use in Large Organizations. MIS Quarterly, Vol 18, September.

Broadbent, M., Weill, P., O’Brien, T., \& Neo, B.S. (1996). Firm Context and Patterns of IT Infrastructure Capability. In Proceedings of the Seventeenth International Conference on Information Systems. New York.

Byrd, T.A., \& Turner, D.E. (2000). Measuring the Flexibility of Information Technology Infrastructure: Exploratory Analysis of a Construct. Journal of Management Information Systems, Vol 17, No 1, Summer, 167-208.

Checkland, P., \& Scholes, J. (1999). Soft Systems Methodology inAction. John Wiley \& Sons Ltd.

Comer, Douglas E. (2001). Computer Networks and Internets. Prentice Hall, Upper Saddle River, NJ.

Davenport, T.H., \& Linder, J. (1994). Information Management Infrastructure: The New Competitive Weapon. In Proceedings of the 2 $7^{\text {th }}$ Annual Hawaii International Conference on Systems Sciences, 885-899.

Dos Santos, B., \& Sussman, L. (2000). Improving the return on IT investment: the productivity paradox. International Journal of Information Management 20, 429-440.

Feeny, David F., \& Willcocks, Leslie P. (1998). Core IS Capabilities for Exploiting Information Technology. Sloan Management Review, Spring, 9-21.

Galliers, R. (1993). Information Analysis: Selected Readings. Addison-Wesley, Great Britain.

Hanseth, O. (1996). Information Infrastructure Development: Cultivating the Installed Base. Studies in the Use of Information Technologies, No 16, Departments of Informatics, Goteborg University.

Hoffer, J.A., George, J., \& Valacich, J. (2001). Modern Systems Analysis and Design. Prentice Hall.

Keen, Peter G.W (1991). Shaping the Future: Business Redesign through Information Technology. Harvard Business School Press. Boston, Massachusetts.

Keen, Peter G.W., \& Cummins, J. Michael (1994). Networks in Action: Business Choices and Telecommunications Decisions. Wadsworth Publishing Company. Belmont, California.

King, W.R. (1978). Strategic planning for management information systems. MIS Quarterly, Vol 2, No 1, 27-37.

Lee, D.M.S., Trauth, E., \& Farwell, D. (1995). Critical skills and knowledge requirements of IS professionals: a joint academic/industry investigation. MIS Quarterly, Vol 19, No 3, 313-340.

Markus, M. Lynne (1991). Systems in Organizations. Cambridge.

Mata, F., Fuerst, W.L., \& Barney, J.B. (1995). Information Technology and Sustained Competitive Advantage: A ResourceBased Analysis, MIS Quarterly, Vol 19, No 4, December.

McKay, D.T., \& Brockway, D.W. (1989). Building I/T Infrastructure for the 1990s. Stage by Stage (Nolan Norton and Co mpany), Vol 9, No 3, 1-11.

Miller, Mark A. (1991). Internetworking: A Guide to Network Communications - LAN to LAN; LAN to WAN. M\&T Publis hing, Inc., Redwood City, California.

Nadig, D.V., \& Hard, N.J. (1993). A Proposed Model for Managing Local Area Networks and Measuring Their Effectiveness. In Proceedings of the 26. Annual Hawaii International Conference on System Sciences, 538-547.

Orlikowski, Wanda J. (1992). The Duality of Technology: Rethinking the Concept of Technology in Organizations. Organization Science, Vol 3, No 3, 398-427.

Rockart, J.F., Earl, M.J., \& Ross, J.W. (1996). Eight Imperatives for the New IT Organization. Sloan Management Review, Vol 38, No 1, Fall, 43-54.

Ross, J.W., Beath, C.M., \& Goodhue, D.L. (1996). Develop Long-Term Competitiveness through IT Assets, Sloan Management Review, 38, Fall, $31-42$.

Schein, Edgar H. (1986). Organizational Culture and Leadership. Jossey-Bass Publishers.

Stallings, W. (2000). Data and Computer Communications. Prentice Hall, Upper Saddle River, NJ.

Todd, P.A., McKeen, J.D., \& Gallupe, R.B. (1995). The Evolution of IS Job Skills: A Content Analysis of IS Job Advertis ements from 1970-1990. MIS Quarterly, Vol 19, No 1, 1-27. 
Turnbull, P.D. (1991). Effective investment in information infrastructures. Information and Software Technology, Vol 33, No 3. 191-199.

Weill, P., \& Broadbent M. (1998). Leveraging the New Infrastructure: How Market Leaders Capitalize on Information Technology. Harvard Business School Press. Boston, Massachusetts.

\section{Biography}

Dr. Seppo Sirkemaa works with Turku School of Economics and Business Administration, Pori unit. His research interests include information technology infrastructure, network management and the role of information technology in education. The writer works also as an IT consultant at sirkemaa.com 